\title{
Prevalence of Pneumonia in Sheep and Goats Slaughtered at Elfora Bishoftu Export Abattoir, Ethiopia: A Pathological Investigation
}

\author{
Berhanu Mekibib ${ }^{D},{ }^{1}$ Tadesse Mikir, ${ }^{2}$ Amene Fekadu, ${ }^{1}$ and Rahmeto Abebe ${ }^{1}$ \\ ${ }^{1}$ Faculty of Veterinary Medicine, Hawassa University, P.O. Box 05, Hawassa, Ethiopia \\ ${ }^{2}$ Field Veterinarian, Ministry of Agriculture and Natural Resources, Amhara Region, Ethiopia \\ Correspondence should be addressed to Berhanu Mekibib; berhanumm2002@gmail.com
}

Received 1 March 2019; Revised 5 April 2019; Accepted 13 June 2019; Published 18 July 2019

Academic Editor: Yves Millemann

Copyright ( 2019 Berhanu Mekibib et al. This is an open access article distributed under the Creative Commons Attribution License, which permits unrestricted use, distribution, and reproduction in any medium, provided the original work is properly cited.

\begin{abstract}
Accurate clinical diagnosis of pneumonia, the leading cause of mortality in small ruminants, is difficult and usually requires postmortem examination of the lungs. An active abattoir survey was conducted between November 2017 and April 2018 to estimate the prevalence and characterize the gross and histopathological lesions of pneumonic lungs in 864 clinically healthy young small ruminants (490 sheep and 374 goats aged 1.5 to 3 years) raised for meat in different parts of the country and slaughtered at Elfora Bishoftu export abattoir, Ethiopia. Out of the total lungs examined grossly, pneumonic lesions were found in 158 (18.29\%) lungs. On histopathological examination of the lungs with gross pneumonic lesion, however, typical pneumonic lesions were diagnosed in $148(17.13 \%)$ lungs only. No significant $(\mathrm{p}>0.05)$ difference was noted in the prevalence of pneumonia between sheep $(17.14 \%)$ and goats (17.11\%) in histopathological examination. Based on the predominant histopathological findings, the pneumonic lesions were characterized as interstitial pneumonia (41.9\%), acute suppurative bronchopneumonia (25.7\%), acute fibrinous bronchopneumonia $(24.3 \%)$, chronic bronchopneumonia $(6.1 \%)$, aspiration pneumonia $(4.7 \%)$, bronchointerstitial pneumonia (3.4\%), and ovine pulmonary adenomatosis (3.4\%). The study further showed the spread of ovine pulmonary adenomatosis and ovine progressive pneumonia (Maedi) from the central highlands to areas that were previously free from these diseases. Due to its better diagnostic capacity, histopathology should be employed routinely as an ancillary test in the major abattoirs and regional veterinary laboratories to generate additional epidemiological data for a better disease control and prevention measures. Further studies are also recommended to identify the etiological agents of pneumonia in sheep and goats and thereby to formulate feasible and cost-effective interventions.
\end{abstract}

\section{Introduction}

Ethiopia has 30.7 million sheep and 30.2 million goats [1]. Despite this huge population, the country is still unable to meet the growing domestic and export need for mutton and chevon because of several reasons. Poor management and husbandry practices and diseases of varied etiologies are among the leading bottlenecks of sheep and goat production [2]. Among the wide range of diseases that affect sheep and goats, respiratory diseases are most frequent as air and blood are their main routes of transmission [3]. Overcrowding coupled with the involuntary inhalation of air polluted with a variety of potentially injurious materials is the most important risk factor for transmission [4].
Lungs are the most exposed organs to different aggressions because of their anatomical and histological particularities [4-6]. The extensive surface area and the delicate vascular bed in the lungs are known to expose the lungs for infection with several pathogens [4]. Pneumonia, a respiratory disease arising from an inflammatory response of the lung parenchyma, is still the major disease limiting the development of animal production in the tropics [7]. In Ethiopia, it is the leading health problem of small ruminants and causes huge financial losses through morbidity and mortality $[2,8,9]$.

Pneumonia is regarded as a disease complex, involving interactions between the host (immunological and physiological), multiple etiological agents (viral, bacterial, 
mycoplasmal, parasitic, etc.), and environmental factors (temperature, humidity, dust levels, etc.) $[10,11]$. Irrespective of the cause, respiratory diseases significantly impact upon the profitability of farms, both directly and indirectly [12] and compromise the welfare of the animals [13]. In general, respiratory ailments are the major cause of death in lambs and decreased productivity in older animals in most developing countries [6].

Clinical diagnosis of pneumonia is difficult and usually involves physical examination, imaging, serology and identification of the aetiological agent from nasal swabs, bronchial lavages, and even feces (for verminous pneumonia) [4, 13, 14]. However, these attempts should be complemented with postmortem examination of the lungs either at necropsy or slaughter for accurate diagnosis $[6,12,14]$. Moreover, because of the poor veterinary services in most parts of Ethiopia, majority of the sheep and goats brought to the abattoir for slaughter may harbor chronic or subclinical infections which are rarely detected during antemortem examination [15]. Therefore, apart from its primary role, an abattoir can also be utilized as an easy and cheap source of data for evaluation of the epidemiological aspects of animal diseases including pneumonia $[16,17]$.

In Ethiopia, some studies have reported that pneumonia is among the major causes of lung condemnation in sheep and goats slaughtered at different abattoirs in the country. According to most recent studies pneumonia was responsible for condemnation of $32.2 \%$ and $60 \%$ of lungs examined at Addis Ababa [18] and Elfora Bishoftu export abattoir [19], respectively. However, to the authors' knowledge, very little work has been done to date to characterize the different forms of pneumonia histopathologically. Thus, the present study was conducted with the objective of estimating prevalence and characterizing the gross and histopathological lesions of pneumonic lungs in sheep and goats slaughtered at Elfora Bishoftu export abattoir.

\section{Materials and Methods}

2.1. Study Area. The study was conducted between November 2017 and April 2018 in Elfora Bishoftu export abattoir, which is located at about 45 kilometers South East of Addis Ababa, the capital city of Ethiopia. It is one of the abattoirs which export meat to Saudi Arabia, Turkey, Egypt and United Arab Emirates. Most of the sheep and goats slaughtered in the abattoir and included in this study originated predominantly from Arsi - Bale highlands and the lowland areas of the country such as Borana zone, south Omo zone, and Arba Minch zuria district (Figure 1).

Arsi-Bale highlands are found in the Oromiya Regional State southeast of Ethiopia. The area majorly represents the central plateau (2000-2500 meters above sea level) and receives a bimodal rainfall occurring from July to October and April to May. The average annual temperature and rain fall ranges between $12-18^{\circ} \mathrm{C}$ and $900-1400 \mathrm{~mm}$, respectively [20].

Arba Minch zuria district is located in southern Ethiopia at about $500 \mathrm{~km}$ from Addis Ababa. The area has an altitude ranging from 1300 to $2600 \mathrm{~m}$ a.s.l. with mean annual rainfall of $900-1000 \mathrm{~mm}$ and mean annual temperature of $23^{\circ} \mathrm{C}$. Therefore, the area has a subhumid climate with moderately hot temperature. The area is characterized by wooded grasslands and riparian vegetation [21].

South Omo zone is located in Southern Nations, Nationalities and People's Regional state (SNNP). The temperature of the area falls between $15.7^{\circ} \mathrm{C}$ and $38^{\circ} \mathrm{C}$. The zone is located in $4.43^{0}-6.46^{\circ}$ North latitude and $35.79^{\circ}-36.06^{\circ}$ East longitude. The climatic condition ranges from Dega (humid) to Kola (semiarid) which constituted $34.4 \%$ of the zonal climatic condition [22].

Borana zone is situated at about $600 \mathrm{kms}$ South of Addis Ababa. The area is bordered by Kenya from south, Somali regional state from east, highlands of Guji from the north and Southern Nation Nationalities, and People Regional State from the west [23]. The climate is generally semiarid with annual average rainfall ranging from $300 \mathrm{~mm}$ in the south to over $700 \mathrm{~mm}$ in the north. Annual mean daily temperature varies from $19^{\circ} \mathrm{C}$ to $24^{\circ} \mathrm{C}$ with moderate seasonal variation. Season affects herding patterns due to its effect on forage and water resources availability [23].

2.2. Study Animals. All the sheep and goats brought to the abattoir were young indigenous breeds raised for meat and milk (goats) production and managed under extensive production system either as part of a mixed crop-livestock production system (in highland areas) or a pastoral system of production (in lowland areas). Sheep and goats are usually kept mixed with other livestock species (cattle, camel, and donkeys) in communal grazing and watering areas. For the purpose of export, they were purchased from different local markets and then transported to the abattoir by lorries and on foot. In the abattoir they were fed, watered, and rested for about 5 to 7 days before slaughter.

2.3. Sample Size and Sampling Procedure. The sample size required for this cross-sectional study was calculated for each species using the formula given by Thrusfield [24]. Using 50\% expected prevalence, 95\% confidence level, and 5\% desired precision, a total of 864 small ruminants (490 sheep and 374 goats) were included in the study. The samplings were done three days per week and on average 30 small ruminants (out of 290 to 320 slaughtered) were sampled and examined each day. These animals were selected by a systematic random sampling whereby every 10th animal walking into the lairage was selected and marked. All study animals were male, local breeds and had medium body conditions. The study animals were aged 1.5 to 3 years as estimated by means of dentition as described for African indigenous goats [25]. For detail histopathological examination, lungs with pneumonic lesions were selected purposively.

\subsection{Methodology}

2.4.1. Gross Examination and Sample Collection. At the abattoir, routine meat inspection was conducted by the local meat inspectors (led by a veterinarian) according to procedures recommended by Gracey et al. [26]. Lungs of the selected study animals suspected of pneumonia were collected and 


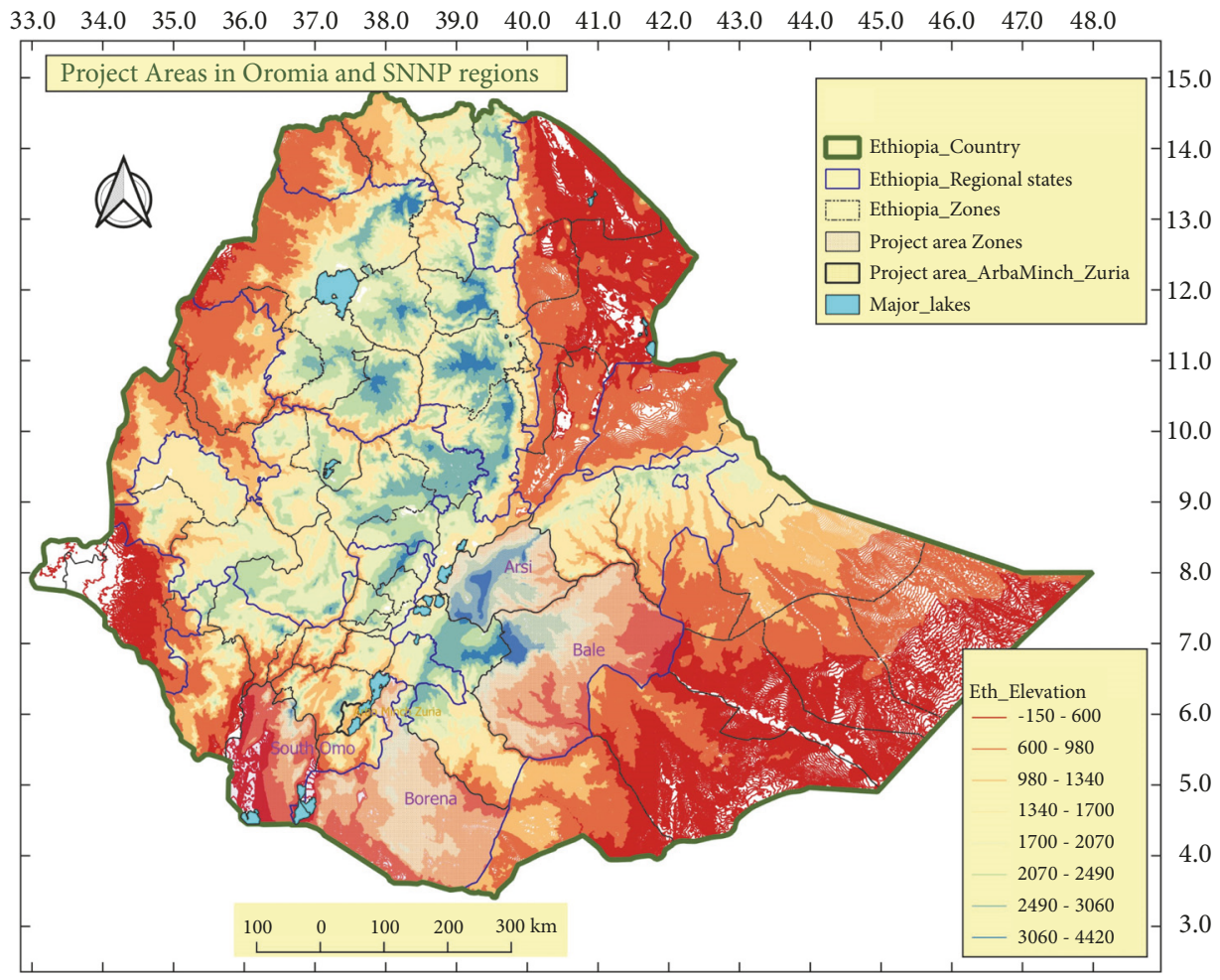

FIGURE 1: Map of the study area showing the elevation and agroclimatic zones.

thoroughly inspected by the first and third authors for the presence of different lesions using visualization, palpation, and multiple systemic incisions when and wherever required. The texture, consistency, color, adhesion, pattern, distribution and number of the lesion(s), the nature of bronchial exudates if any, and the lobe(s) involved were recorded on a format prepared for this purpose. Representative pieces of tissues (4-5 $\mathrm{mm}$ in thickness) were then taken from the pneumonic lungs, fixed with $10 \%$ neutral buffered formalin, and transported to Hawassa University, Veterinary Pathology and Parasitology Laboratory.

2.4.2. Histopathological Examination. Following at least 48 hrs of fixation, representative tissue samples were properly trimmed, labeled, and processed by a routine paraffinembedded technique. Briefly, the fixed tissue samples were cut into pieces of 2-3 mm thickness and washed thoroughly with water for several hours before putting in ascending grades of alcohol for dehydration, followed by clearance in xylene and embedded in paraffin. Sections of 4-5 micron thickness were cut and stained by Harri's hematoxylin and Eosin method [27]. Finally the stained slides were examined systematically at $10 \mathrm{X}$ and $100 \mathrm{X}$ magnifications for the presence of characteristic and/or suggestive lesions using ordinary light microscope. The different forms of pneumonia were then classified according to the involvement of pulmonary regions and anatomical sites and nature of the inflammatory exudate and reaction present $[28,29]$.

2.5. Data Management and Analysis. Data obtained during antemortem, gross, and histopathological examinations were recorded on Microsoft excel spread sheet. The difference in the prevalence of pneumonia between sheep and goats was analyzed using chi-square independent test. A p value $<0.05$ was considered statistically significant.

\section{Results}

Out of the total of 864 small ruminants' lungs subjected to gross examination, pneumonic lesions were detected in the lungs of 158 (18.29\%) animals. However, on histopathological examination of the suspected lesions, pneumonia was diagnosed in 148 (17.13\%) animals only. The pneumonia suspected in the lungs of the other 10 animals during gross examination was histopathologically confirmed to be nonpneumonic pneumopathies, namely, hemorrhage $(n=8)$ and atelectasis $(n=2)$. The prevalence of pneumonia was quite similar in both sheep and goats $(\mathrm{p}>0.05)$ (Table 1$)$.

On the basis of predominant histopathological findings, the pneumonic lesions were further classified into interstitial pneumonia, acute suppurative bronchopneumonia, acute fibrinous bronchopneumonia, chronic bronchopneumonia, aspiration pneumonia, bronchointerstitial pneumonia, and ovine pulmonary adenomatosis. The three forms of bronchopneumonia altogether accounted for $56.1 \%(n=83)$ of the pneumonic lungs observed. Of the total pneumonic animals, six animals were affected with two types of pneumonia while four animals were with three forms (Table 2).

3.1. Interstitial Pneumonia. Interstitial pneumonia was encountered in $41.9 \%$ of the animals with gross pneumonic lesions. Grossly, most parts of the lungs were enlarged, 
TABLE 1: Prevalence of pneumonia in the lungs of sheep and goats based on gross and histopathological examinations.

\begin{tabular}{|c|c|c|c|c|c|}
\hline \multirow{2}{*}{ Animal } & \multirow{2}{*}{ Total examined } & \multicolumn{2}{|c|}{ Gross examination } & \multicolumn{2}{|c|}{ Histopathological examination } \\
\hline & & No (\%) positive & $95 \% \mathrm{CI}$ & No (\%) positive & $95 \% \mathrm{CI}$ \\
\hline Sheep & 490 & $89(18.16)$ & $14.7-21.6$ & $84(17.14)$ & $13.8-20.5$ \\
\hline Goats & 374 & $69(18.45)$ & $14.5-22.4$ & $64(17.11)$ & $13.3-20.9$ \\
\hline Total & 864 & $158(18.29)$ & $15.7-20.9$ & $148(17.13)$ & $14.6-19.6$ \\
\hline
\end{tabular}

TABLE 2: Types of pneumonia found in sheep and goats by histopathological diagnosis.

\begin{tabular}{lccc}
\hline Types of pneumonia & Sheep $(\mathrm{n}=84)$ & Goat $(\mathrm{n}=64)$ & \multicolumn{2}{c}{ Overall $(\mathrm{n}=148)$} \\
& No $(\%)$ & No $(\%)$ & No $(\%)$ \\
\hline Interstitial pneumonia & $43(51.2)$ & $19(29.7)$ & $62(41.9)$ \\
Acute suppurative bronchopneumonia & $15(17.9)$ & $23(35.9)$ & $38(25.7)$ \\
Acute fibrinous bronchopneumonia & $16(19)$ & $20(31.3)$ & $36(24.3)$ \\
Chronic bronchopneumonia & $7(8.3)$ & $3(3.1)$ & $9(6.1)$ \\
Aspiration pneumonia & $4(4.8)$ & - & $7(4.7)$ \\
Ovine pulmonary adenomatosis & $5(6)$ & $3(4.7)$ & $5(3.4)$ \\
Broncho-interstitial pneumonia & $2(2.4)$ & & $5(3.4)$ \\
\hline
\end{tabular}

rubbery in consistency and meaty in appearance (Figure 2(a)). The lungs had rib imprints and the lesions were generalized but predominantly dispersed on the caudal aspect of the lungs. Microscopically, the lesions were characterized by thickening of the interalveolar septa because of proliferation of smooth muscle and fibroblasts along with infiltration with lymphocytes, neutrophils, and macrophages (Figure 2(b)). Moreover, lymphofollicular proliferation with follicle-like aggregations, peribronchial and perivascular cuffing (Figure 2(b) Inset) and thrombus were noted in $45 \%$ of the cases with interstitial pneumonia. Unlike the bronchopneumonia cases, there was no obvious exudate in the alveolar spaces and airways. This form of pneumonia was also seen concurrently with acute fibrinous bronchopneumonia $(n=5)$ and acute suppurative bronchopneumonia $(\mathrm{n}=1)$.

3.2. Acute Suppurative Bronchopneumonia. Acute suppurative bronchopneumonia (ASBp) was detected in $25.7 \%$ of the pneumonic animals. Grossly the lungs were red to gray in color, consolidated in consistency, and sometimes caeseous upon incision. The lesions were mainly distributed to the cranioventral aspects of the lungs (Figure 3(a)). Histopathologically, the suppurative areas were characterized by infiltration of polymorphonuclear cells (mainly neutrophils) and few mononuclear cells in the alveoli, bronchi, and bronchioles (Figure 3(b)). Sloughed epithelial cells and necrotic debris were also noted in the bronchi and bronchioles. Moreover, bacterial colonies were noticed in the alveoli of some cases.

3.3. Acute Fibrinous Bronchopneumonia. Acute fibrinous bronchopneumonia (AFBp) was observed in $24.3 \%$ of the affected animals. The lesions were grossly characterized by areas of consolidation mostly in the cranial, cardiac, and accessory lobes (Figure 4(a)). The lungs were hard to cut and some cases showed marbling with thickening of interlobular septa and pleura. Histopathologically, the lesions were characterized by exudation in the bronchi, bronchioles, and alveoli majorly composed of fibrin and neutrophils, denuded epithelial cells, and necrotic debris. Interlobular septa were thickened with infiltration of fibrinocellular exudates comprising predominantly of neutrophils with occasional mononuclear cells (Figure $4(\mathrm{~b})$ ). In some $(\mathrm{n}=11)$ cases, desquamation of epithelial cells, spindle-shaped cells, oat streaming cells, and syncytial cells were also noted.

3.4. Chronic Bronchopneumonia. Chronic bronchopneumonia (CBp) was seen in $6.1 \%$ of the affected animals. It mainly involved the cranial lobes, and the lesions in the affected parts were firm to hard in consistency and pale to gray in color. The pleura were shriveled and adhered to the chest wall in three cases. Microscopically, extensive fibrinous thickening of the pleura and varying degree of mononuclear cells infiltration in the alveoli were observed (Figure 5).

3.5. Bronchointerstitial Pneumonia. The lesions suggestive of bronchointerstitial pneumonia were observed in $3.4 \%$ of the affected animals ( 2 sheep and 3 goats). Grossly, the lesions were not remarkable but the affected parts were meaty in appearance, uncollapsed, and distributed on both the anterior and caudal lobes. Microscopically, the characteristic features of both suppurative bronchopneumonia and interstitial pneumonia were found admixed (Figure 6).

3.6. Aspiration Pneumonia. Microscopic lesions typical of aspiration pneumonia were detected in $4.7 \%$ of the affected animals. Of these animals, four had prominent atelectasis mainly on the cranioventral aspect of their lungs. Grossly, the affected portions of the lungs were congested and somewhat meaty in consistency. Moreover, gray to green-brown foulsmelling exudates were expressed from small airways upon compression in three lungs (Figure 7(a)). Microscopically, the 


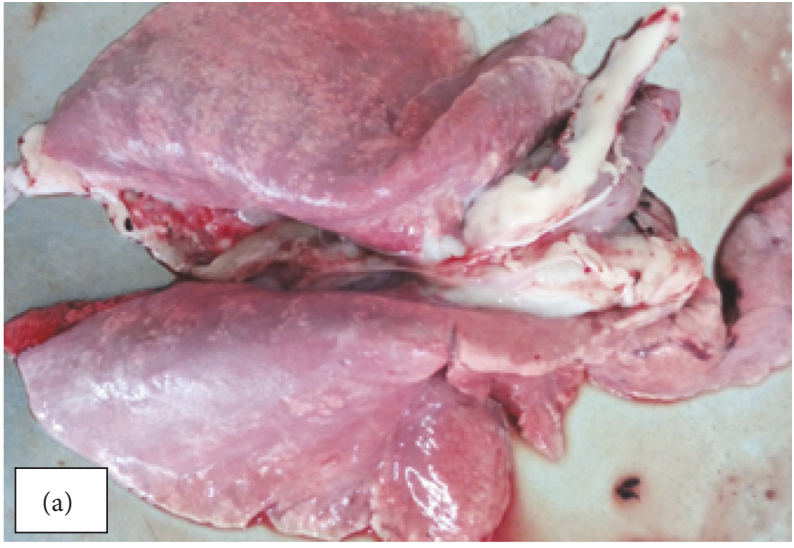

(a)

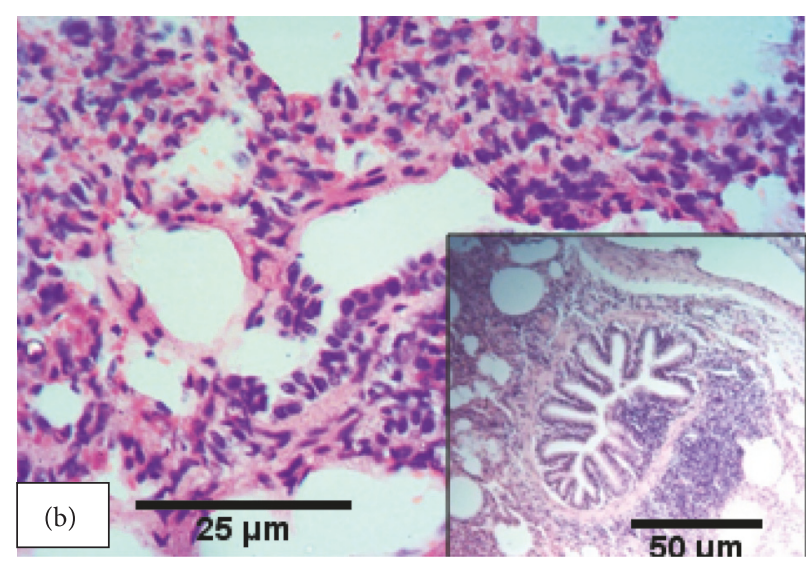

(b)

FIGURE 2: Interstitial pneumonia: enlarged lungs with rib imprint, rubbery in consistency, and meaty in appearance (a) and thickening of the interalveolar septa because of proliferation of smooth muscle and fibroblasts along with inflammatory cells infiltration (b).

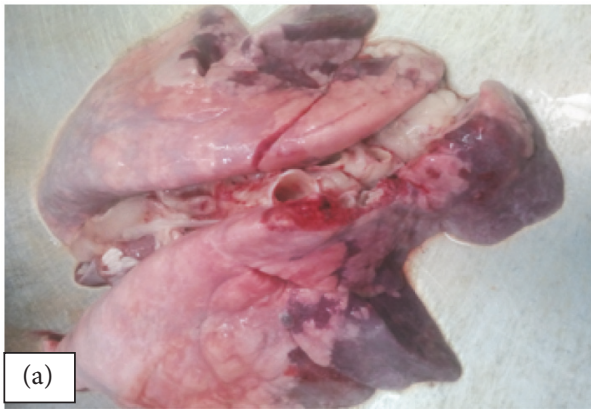

(a)

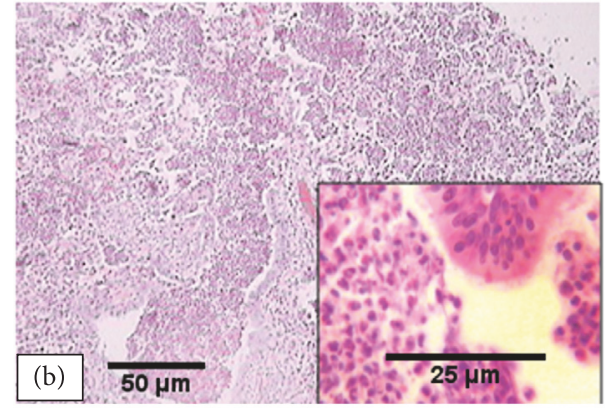

(b)

FIGURE 3: Acute suppurative bronchopneumonia: red to gray cranioventral lobes (a) with characteristic polymorphonuclear cells and few mononuclear cells infiltration in the alveoli, bronchi, and bronchioles (b).

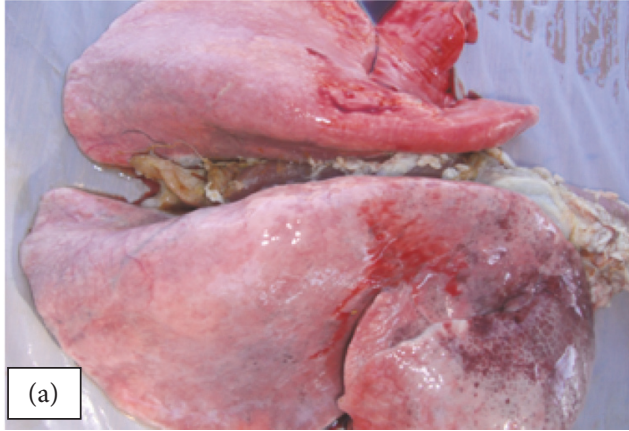

(a)

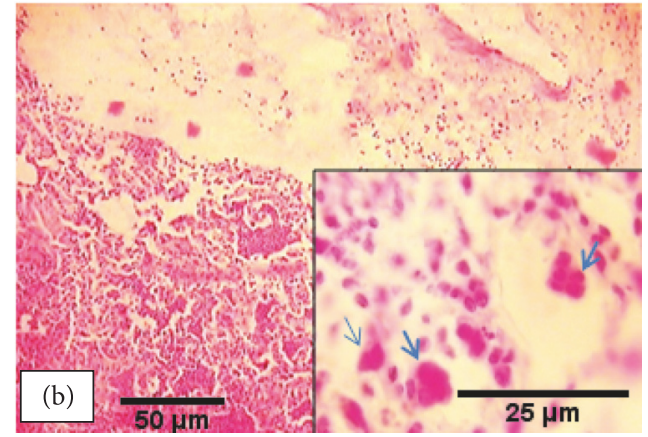

(b)

FIGURE 4: Acute fibrinous bronchopneumonia: consolidation and mottling on cranial lobes (a) with marked fibrinopurulent exudates and syncytial cells (arrow) in the alveoli, bronchi, and bronchioles (b).

lesions were ranging from bronchopneumonia to granulomatous in type but all were characterized by the presence of aspirated/foreign material in the bronchi and bronchioles (Figure 7(b)).

3.7. Ovine Pulmonary Adenomatosis (OPA). Ovine pulmonary adenomatosis (OPA) was found in $3.4 \%$ of pneumonic animals, all of which were sheep. It was found as concurrent infection with fibrinous bronchopneumonia and ovine progressive pneumonia, one case each. Grossly, the lungs were enlarged, heavier, grayish to white granular masses with meaty to firm in consistency (Figure 8(a)). Moreover, grayish exudates were appreciated from cut surfaces of variably sized elevated nodules. Microscopically, the lesions were characterized by papillomatous proliferation of type II pneumocytes that project into the alveoli (Figure 8(b)). Apart 


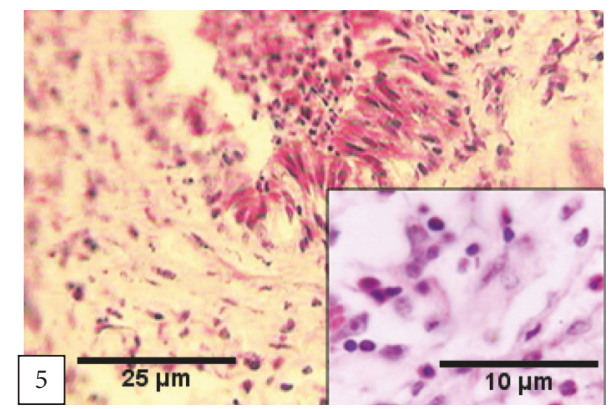

Figure 5: Chronic bronchopneumonia: extensive fibrinous thickening of the pleura and varying degree of mononuclear cells infiltration in the alveoli.

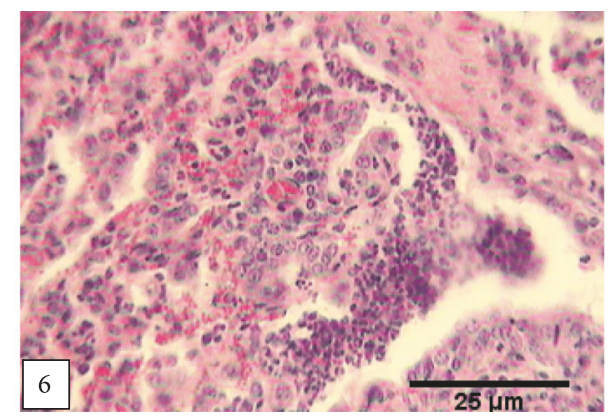

FIGURE 6: Bronchointerstitial pneumonia: thickening of intraalveolar septa with prominent exudate in the alveoli and respiratory tree.

from the adenomatous appearance, neutrophilic aggregates were also observed in the lumen of alveoli, bronchioles, and bronchi of 1 lung and characteristic lesion in others.

\section{Discussion}

Respiratory diseases, particularly pneumonia, constitute significant economic losses after diarrhea in small ruminants [30]. In Ethiopia, respiratory diseases of sheep caused by concurrent infections have been identified as the leading health problem accounting for more than half of the overall mortality of sheep in the central highlands [8]. The current study revealed that $17.14 \%$ of sheep and $17.11 \%$ of goats examined at an export abattoir had pneumonic lesions showing that the condition is an important cause of organ condemnation and thereby economic losses.

In the present study, bronchopneumonia in the form of acute suppurative, acute fibrinous, and chronic bronchopneumonia accounted for the greatest proportion $(56.1 \%)$ of pneumonia encountered. In agreement with the present finding, previous investigations in other countries also reported bronchopneumonia as the commonest type of pneumonia in sheep and goats $[28,29,31,32]$. The gross and histological lesions of the different forms of bronchopneumonia were consistent with the findings of other studies [11, 33-36]. The lesions could be associated with contagious caprine pleuropneumonia (in goats) or pneumonic pasteurellosis as these diseases are characterized by fibrinous and suppurative bronchopneumonia patterns $[4,37,38]$. These specific pneumonic diseases were also reported to be prevalent in some parts of Ethiopia [39-41]. The majority (89.2\%) of bronchopneumonia noted in the current study was acute type. This suggests that the disease was most likely attributed to exposure of the animals to various stresses during transportation for slaughter. Stress factors like long transportation under poor condition, overcrowding, sudden climate change at transit, unrest in the lairage, inadequate feed and water provision, and other underling diseases including predisposing viral infection of the respiratory system such as parainfluenza3 , adenoviruses, and respiratory syncytial virus are widely accepted as predisposing factors for bacterial pneumonia $[4,42]$.

Although bronchopneumonia is multifactorial in origin, it is mainly caused by bacterial pathogens, namely, Mannheimia haemolytica, Pasteurella multocida, Histophilus somni, and Mycoplasma spp. when the immune system of the animal is compromised by aforementioned stress factors [4, 42]. The above bacteria and other opportunistic bacteria were isolated from the respiratory tract of healthy and pneumonic sheep and goats in different parts of the country [43-48].

Interstitial pneumonia was the second dominant type of pneumonia in this study detected in $41.9 \%$ of the pneumonic animals. The gross and histopathological characteristics of the lesions in the affected lungs were similar to earlier reports $[11,49,50]$. It was appreciated in both species; however, the proportion was considerably higher in sheep (51.2\%) than in goats $(29.7 \%)$. Although some environmental factors are rarely incriminated, interstitial pneumonia in small ruminants is mainly caused by two related viral pathogens, namely, ovine lentivirus (OvLV) in sheep and Caprine arthritisencephalitis virus (CAEV) in goats, and usually referred as lentiviral pneumonia [4]. Unless complicated with other pathogens, this form of pneumonia is usually subclinical and only detected during histopathology [51]. Ovine progressive pneumonia (also known as Maedi), a chronic disease of sheep caused by OvLV, has been reported from different parts of the country through serological, histopathological, and clinical studies [44, 52-58]. According to the studies, the seroprevalence of ovine progressive pneumonia in Ethiopia ranges from $5.4 \%$ to $74 \%$. Following its first report in 1991 in Agarfa and Arsi Rural Development Unit (ARDU) exotic sheep breeding farms/centers, there is a growing evidence for the dissemination of the disease to several parts of the country through the distribution of exotic or cross breed rams from the breeding and multiplication center [54]. Although lentiviral pneumonia was not reported previously in goats in the country, the interstitial pneumonia observed in this species might be caused by Caprine arthritis-encephalitis virus (CAEV) and/or Maedi-Visna virus infection. While further confirmatory research is needed, the authors suspect the introduction of the strains into local goats following the attempt made during the past one decade to improve the productivity of the local goat population by importing exotic goat breeds. Moreover, the greater homology of CAEV to ovine lentivirus (OvLV) and the interspecies transmission of these viruses necessitate comparative phylogeny of small ruminant lentiviruses [4]. 


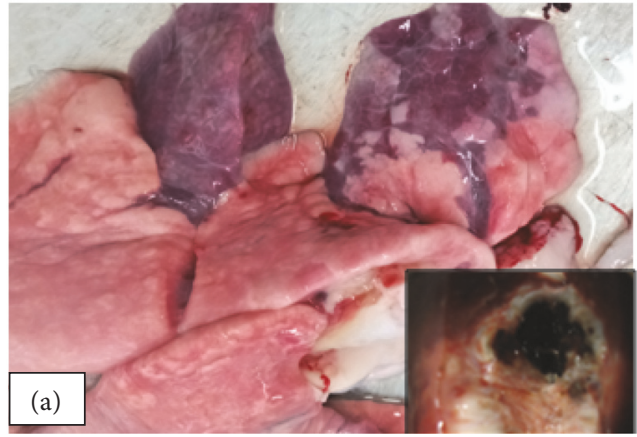

(a)

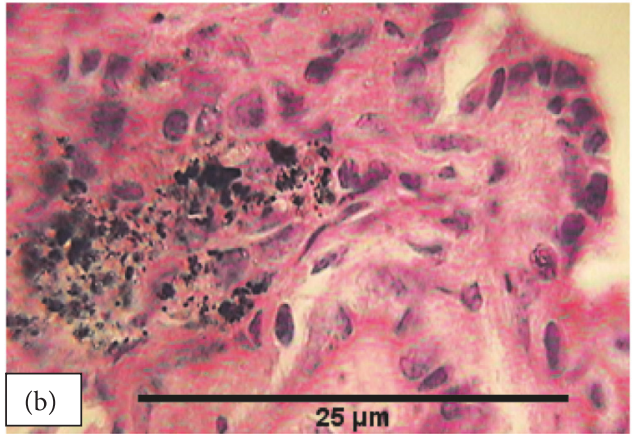

(b)

FIGURE 7: Aspiration pneumonia: atelectasis on the cranioventral lobes with green-brown contents in the air ways (a) suggesting foreign body granuloma (b).

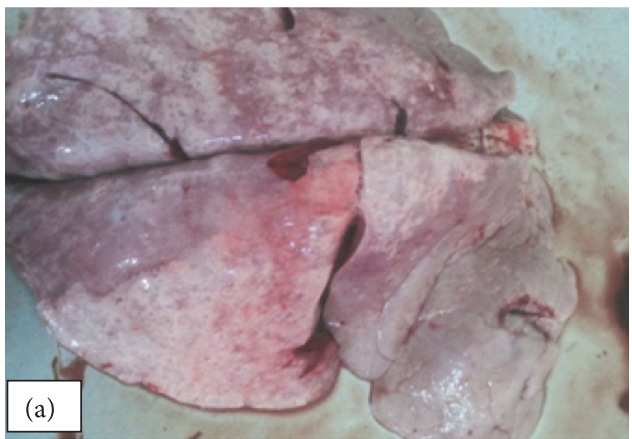

(a)

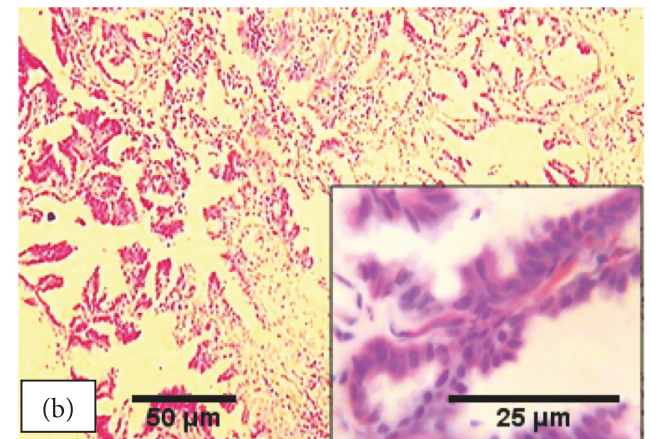

(b)

FIGURE 8: Ovine Pulmonary adenomatosis: enlarged, heavier, grayish to white granular masses with meaty to firm in consistency (a) with characteristic papillomatous proliferation of type II pneumocytes that project into the alveoli (b).

Lesions suggestive of bronchointerstitial pneumonia were observed in 2 sheep $(2.4 \%)$ and 3 goats $(4.7 \%)$. The gross and microscopic features detected in this study were consistent with the previous reports [34]. Bronchointerstitial pneumonia happens when viral agents affect the lungs as the primary etiology of interstitial pneumonia with further invasion of the infected lungs by bacteria [34]. Bronchointerstitial pneumonia, among others, is widely accepted as the novel pathologic finding observed in natural Peste des Petits Ruminants (PPR) virus infection in sheep and goats $[4,59-61]$. Several studies have reported the presence of PPR in Ethiopia particularly in pastoral areas with huge small ruminant potential [62-65]. Mycoplasma ovipneumoniae is also incriminated as a cause of atypical or chronic progressive pneumonia in sheep with an interstitial bronchopneumonia pattern [66]. The majority of these strains were detected by dot blot test on pneumonic lung extracts and pleural exudate samples collected from respiratory cases that occurred in different regions in Ethiopia [67].

Aspiration pneumonia was detected in both sheep (4.8\%) and goats $(4.7 \%)$ with equal proportions and more or less the same gross and histopathological findings. The observed lesions were similar with the reports of Caswell and Williams [4] and Antoniassi et al. [68]. The gross and microscopic lesions of aspiration pneumonia are greatly variable and usually depend on the physical and chemical nature of the aspirated material. Apart from the inherent inflammatory and necrotic nature of the aspirated fluid, most bacteria from the nasopharynx will be flushed down the respiratory tree and reach the lungs by gravitational drainage and cause lesions ranging from bronchopneumonia to granulomatous in type $[69,70]$. The common conditions predisposing small ruminants to aspiration pneumonia include poor dipping techniques, faulty administration or drenching of milk or medicaments, presence of cleft palate, and some infectious and neurologic diseases causing laryngeal dysfunction [71]. Perhaps, faulty administration or drenching of medicaments took the lead because of the prevailing shortage of veterinary service in the study areas where these animals originated.

Ovine pulmonary adenocarcinoma (OPA), also known as Jaagsiekte disease, was the least form of pneumonia that was detected in only five sheep. The gross and histopathologic features observed were classic and similar to the previous reports from Ethiopia and elsewhere [36, 55, 58, 72]. Concurrent infection of OPA with suppurative bronchopneumonia and ovine progressive pneumonia was also reported earlier by Woldemeskel and Tibbo [55]. Previous reports of OPA in Ethiopia were from the central highlands of the country 
$[55,58]$. In contrast, the current study revealed for the first time the presence of the disease in Borena ( 5 cases) and Arsi (1 case), which are representative of typical pastoral lowland and central plateau, respectively. The gradual spread of the disease to other parts of the country can partly be explained by the unrestricted transportation of animals from place to place and the widespread distribution of improved breeds from breeding centers located at central highlands. Owing to the long incubation period and the subclinical form of the disease, its spread to other parts of the country probably increases in multiple folds. Since the existing serological tests fail to diagnose the disease [73, 74], similar abattoir based studies are crucial to study the spatial distribution of the disease and hence take the necessary control and preventive measures.

\section{Conclusion}

In general, the current histopathological study unveiled that more than $17 \%$ of sheep and goats slaughtered at Elfora abattoir were affected with different forms of pneumonia. Bronchopneumonia and interstitial pneumonia were the major forms of pneumonia detected. As most of the pulmonary disease was diagnosed as acute while the animals were held alive in pens at the abattoir prior to slaughter, reducing this period to the minimum could significantly reduce the magnitude. Apart from its better sensitivity and specificity, the histopathologic diagnosis of lungs potentially helped to survey the various forms of pneumonia occurring in different corners of the country. Therefore, histopathology should be employed routinely as an ancillary test in the major abattoirs and regional veterinary laboratories to generate additional epidemiological data for a better disease control and prevention measures. Further studies focusing on the spatial distribution of the different pneumonic diseases and isolation of the causative agents are also required to formulate feasible and cost-effective control strategies.

\section{Data Availability}

The data used to support the findings of this study are available from the corresponding author upon request.

\section{Conflicts of Interest}

The authors declare that there are no conflicts of interest regarding the publication of this paper.

\section{Authors' Contributions}

Berhanu Mekibib, Tadesse Mikir, and Amene Fekadu were responsible for the study design, sample collection, and processing. Berhanu Mekibib and Rahmeto Abebe were involved in slide reading and interpretation of the results and the data at large. Berhanu Mekibib and Tadesse Mikir prepared the draft manuscript. All authors have read and approved the final manuscript.

\section{Acknowledgments}

We extend our gratitude to the staff members of Elfora Bishoftu export abattoir for their cooperation and technical support during data collection. Special thanks also go to Dr. Tilaye Demisse and the technical assistants working at the pathology laboratories of the College of Veterinary Medicine (Addis Ababa University) and Faculty of Veterinary Medicine (Hawassa University) for their all-round support and material provision. We are also grateful to Drs. Zerihun woldesenbet and Gizachew Hailegebreal for their assistance in map preparation.

\section{References}

[1] Central Statistical Agency (CSA), "Agricultural sample survey 2016/17 (2009 E.C.), volume II: report on livestock and livestock characteristics (private peasant holdings)," Statistical Bulletin 585, Addis Ababa Ethiopia, Federal Democratic Republic of Ethiopia, 2017.

[2] B. Molla, "The health performance of imported Boer goat (Capra hircus) and their crosses with Woito-guji goat breeds in South Omo Zone, South-Western Ethiopia," Tropical Animal Health and Production, vol. 48, no. 4, pp. 855-861, 2016.

[3] S. Tesfaye and N. Mekonnen, "A study on major causes of organs condemnation and their financial losses in cattle slaughtered at Gondar ELFORA abattoir, Northwestern, Ethiopia," Global Veterinaria, vol. 17, pp. 365-374, 2016.

[4] J. L. Caswell and K. J. Williams, "Respiratory system," in Jubb, Kennedy and Palmer Pathology of Domestic Animals, M. G. Maxie, Ed., vol. 5th, pp. 524-650, Elsevier, Edinburgh, Scotland, 2007.

[5] M. Belkhiri, M. Tlidjane, Y. Benhathat, and T. Meziane, "Histopathological study and pulmonary classification of bovine lesions," African Journal of Agricultural Research, vol. 4, no. 7, pp. 584-591, 2009.

[6] L. M. Dar, M. M. Darzi, M. S. Mir, S. A. Kamil, A. Rashid, and S. Abdullah, "Prevalence of lung affections in sheep in northern temperate regions of India: A postmortem study," Small Ruminant Research, vol. 110, no. 1, pp. 57-61, 2013.

[7] V. Attoh-Kotoku, B. O. Emikpe, and D. Obuadey, "Patterns and direct financial implications of contagious pleuropneumonia in cattle slaughtered in Kumasi Abattoir, Ghana," Animal Research International, vol. 15, pp. 2937-2943, 2018.

[8] E. Mukasa-Mugerwa, A. Lahlou-Kassi, D. Anindo et al., "Between and within breed variation in lamb survival and risk factors associated with major causes of mortality in indigenous tropical sheep," Small Ruminant Research, vol. 33, pp. 1-12, 2000.

[9] S. Gizaw, A. Tegegne, B. Gebremedhin, and D. Hoekstra, "Sheep and goat production and marketing systems in Ethiopia: Characteristics and strategies for improvement," in Proceedings of the IPMS (Improving Productivity and Market Success) of Ethiopian Farmers Project Working Paper 23, p. 58, Nairobi, Kenya, 2010.

[10] J. D. Taylor, R. W. Fulton, T. W. Lehenbauer, D. L. Step, and A. W. Confer, "The epidemiology of bovine respiratory disease: What is the evidence for predisposing factors?" Canadian Veterinary Journal, vol. 51, no. 10, pp. 1095-1102, 2010.

[11] L. Dar, M. Darzi, M. Mir et al., "Histopathological and histoenzymatic studies on bronchopneumonia in sheep," Journal of Applied Animal Research, vol. 42, no. 3, pp. 289-296, 2014. 
[12] A. Di Provvido, G. Di Teodoro, G. Muuka, G. Marruchella, and M. Scacchia, "Lung lesion score system in cattle: proposal for contagious bovine pleuropneumonia," Tropical Animal Health and Production, vol. 50, no. 1, pp. 223-228, 2018.

[13] S. Bell, "Respiratory disease in sheep," In Practice, vol. 30, no. 278-283, 2008.

[14] K. M. McRae, H. J. Baird, K. G. Dodds, M. J. Bixley, and S. M. Clarke, "Incidence and heritability of ovine pneumonia, and the relationship with production traits in New Zealand sheep," Small Ruminant Research, vol. 145, pp. 136-141, 2016.

[15] L. S. B. Mellau, H. E. Nonga, and E. D. Karimuribo, "A slaughterhouse survey of lung lesions in slaughtered stocks at Arusha, Tanzania," Preventive Veterinary Medicine, vol. 97, no. 2, pp. 77-82, 2010.

[16] D. S. Edwards, A. M. Johnston, and G. C. Mead, "Meat inspection: An overview of present practices and future trends," The Veterinary Journal, vol. 154, no. 2, pp. 135-147, 1997.

[17] G. Schweizer, G. F. Plebani, and U. Braun, "Prevalence of Fasciola hepatica and Dicrocoelium dendriticum in the cow: inspection in an east Switzerland abattoir," SAT Schweizer Archiv für Tierheilkunde, vol. 145, no. 4, pp. 177-179, 2003.

[18] D. Assefa, E. Gezaheng, B. Abera, E. Eticha, D. Lemma, and T. Hailemariam, "Major cause of organ and carcass condemnation in apparently healthy small ruminant slaughtered at Addis Ababa Abattoir enterprise, Ethiopia," Journal of Veterinary Science \& Technology, vol. 8, no. 419, 2017.

[19] A. Mandefro, "Major cause of organ and carcass condemnation and its financial loss at Bishoftu Elfora Export Abattoir," International Journal of Nutrition and Food Sciences, vol. 4, no. 3, pp. 364-372, 2015.

[20] H. Yacob and A. Hagos, "Epidemiological study on Gastrointestinal Helminths of horses in Arsi-Bale highlands of Oromiya Region, Ethiopia," Ethiopian Veterinary Journal, vol. 17, no. 5162, 2013.

[21] K. Girma, T. Meseret, Z. Tilahun et al., "Prevalence of bovine trypanosomosis, its vector density and distribution in and around Arbaminch, Gamogofa Zone, Ethiopia," Acta Parasitologica Globalis, vol. 5, pp. 169-176, 2014.

[22] South Omo Zone Agricultural office, "Annual report on zonal livestock production Jinka, Ethiopia," 2006.

[23] D. L. Coppock, "Climate, primary production and carrying capacity of the Borona plateau," in The Borana Plateau of Southern Ethiopia, Synthesis of Pastoral Research, Development and Change, ILCA, Addis, 1994.

[24] M. Thrusfield, Veterinary Epidemiology, John Wiley \& Sons Ltd, 4th edition, 2018.

[25] M. Steele, "Goats," in The Tropical Agriculturist, Macmillan Education Ltd., London and Technical Center for Agricultural and Rural Co-Operation (CTA), Wageningen, 1996.

[26] J. F. Gracey, D. S. Collins, and R. J. Huey, Meat Hygiene, W.B. Saunders Company, Ltd, 10th edition, 1999.

[27] L. G. Luna, Manual of Histologic Staining Methods of the Armed Forces Institute of Pathology, Mc Graw Hill, New York, NY, USA, 7th edition, 1968.

[28] R. Singh, P. Kumar, M. Sahoo et al., "Spontaneously occurring lung lesions in sheep and goats," Indian Journal of Veterinary Pathology, vol. 41, pp. 18-24, 2017.

[29] S. Mishra, P. Kumar, N. George, R. Singh, and V. Singh, "survey of lung affections in sheep and goats: a slaughterhouse study," Journal of Entomology and Zoology Studies, vol. 6, pp. 118-120, 2018.
[30] A. Dohare, B. Singh, Y. Bangar, S. Prasad, D. Kumar, and G. Shakya, "Influence of age, sex and season on morbidity and mortality pattern in goats under village conditions of Madhya Pradesh," Veterinary World, vol. 6, no. 6, pp. 329-331, 2013.

[31] R. K. Sharma, B. R. Boro, and P. Borah, "Incidence of caprine pneumonia and associated bacterial species," Indian Journal of Animal Sciences, vol. 61, pp. 54-55, 1991.

[32] J. A. Dar, Monitoring and pathology of viral pneumonias with special reference to retroviral infections in sheep and goats, [MVSc Thesis], Deemed University, Indian Veterinary Research Institute, Izatnagar, India, 2017.

[33] E. Oruc, "The pathologic and bacteriologic comparison of pneumonia in lambs," Turkish Journal of Veterinary and Animal Sciences, vol. 30, pp. 593-599, 2006.

[34] S. Azizi, F. S. Korani, and A. Oryan, "Pneumonia in slaughtered sheep in south-western Iran: Pathological characteristics and aerobic bacterial aetiology," Veterinaria Italiana, vol. 49, no. 1 , pp. 109-118, 2013.

[35] A. A. Mahdi, A. A. Al-Naqshabendy, and B. T. Haddel, "A Study of some pathological lesions in the lung of sheep goats at Duhok abattoir," Basrah Journal Veterinary Research, vol. 14, pp. 265$277,2015$.

[36] M. A. Kumar, R. Kumar, K. Varshney et al., "Pathomorphological studies of lung lesions in sheep," Indian Journal of Veterinary Pathology, vol. 38, no. 2, pp. 75-81, 2014.

[37] S. Sadeghian, M. R. Dezfouli, G. A. Kojouri, T. T. Bazargani, and A. Tavasoli, "Pasteurella multocida pneumonic infection in goat: Hematological, biochemical, clinical and pathological studies," Small Ruminant Research, vol. 100, no. 2-3, pp. 189-194, 2011.

[38] P. D. Constable, K. W. Hinchcliff, S. H. Done, and W. Gruenberg, Veterinary Medicine: A Textbook of The Diseases of Cattle, Horses, Sheep, Pigs and Goats, Saunders, Elsevier, 11th edition, 2012.

[39] L. Yigezu, S. Tariku, G. Ayelet, and F. Roger, "Respiratory mycoplasmosis of small ruminants in Ethiopia," Ethiopian Veterinary Journal, vol. 8, pp. 67-74, 2004.

[40] E. Yousuf, E. Melaku, and B. Bogale, "Seroprevalence of contagious caprine pleuropneumonia in Dire Dawa provisional administrative council, Eastern Ethiopia," Journal of Veterinary Medicine and Animal Health, vol. 4, no. 7, pp. 93-96, 2012.

[41] S. Haji and F. Abunna, "Epidemiology of ovine pasteurollosis in Lume district, East Shewa zone of Oromiya region," Journal of Biology, Agriculture and Healthcare, vol. 6, pp. 12-20, 2015.

[42] A. U. N'jai, J. Rivera, D. N. Atapattu, K. Owusu-Ofori, and C. J. Czuprynski, "Gene expression profiling of bovine bronchial epithelial cells exposed in vitro to bovine herpesvirus 1 and Mannheimia haemolytica," Veterinary Immunology and Immunopathology, vol. 155, no. 3, pp. 182-189, 2013.

[43] G. Shiferaw, S. Tariku, G. Ayelet, and Z. Abebe, "Contagious caprine pleuropneumonia and Mannheimia haemolytica -associated acute respiratory disease of goats and sheep in Afar Region, Ethiopia," Revue Scientifique Et Technique (International Office of Epizootics), vol. 25, no. 3, pp. 1153-1163, 2006.

[44] L. Garedew, G. Ayelet, R. Yilma, A. Zeleke, and E. Gelaye, "Isolation of diverse bacterial species with maedi-visna infection of sheep in Ethiopia," African Journal Microbiology Research, vol. 4, pp. 14-21, 2010.

[45] H. D. Marru, T. T. Anijajo, and A. A. Hassen, "A study on Ovine pneumonic pasteurellosis: Isolation and Identification of Pasteurellae and their antibiogram susceptibility pattern in Haramaya District, Eastern Hararghe, Ethiopia," BMC Veterinary Research, vol. 9, article no 239, 2013. 
[46] B. Tesfaye, T. Sisay Tessema, and G. Tefera, "Diversity of bacterial species in the nasal cavity of sheep in the highlands of Ethiopia and first report of Histophilus somni in the country," Tropical Animal Health and Production, vol. 45, no. 5, pp. 12431249, 2013.

[47] M. Asaye, H. Biyazen, and M. Bezie, "Isolation and characterization of respiratory tract bacterial species from domestic animals with pneumonic lungs from Elphora abattoir, Ethiopia," International Journal of Microbiological Research, vol. 6, pp. 1319, 2015.

[48] S. Hailu, D. Kitila, A. Gemeda, and M. Tarekegn, "Pasteurella organism: Its isolation and identification from pneumonic lungs of goats in Ethiopia," Journal of Advanced Veterinary and Animal Research, vol. 4, no. 2, pp. 147-154, 2017.

[49] N. Hailat, O. Al-Rawashdeh, S. Lafi, and Z. Al-Bateineh, "An outbreak of sheep pox associated with unusual winter conditions in Jordan," Tropical Animal Health and Production, vol. 26, no. 2, pp. 79-80, 1994.

[50] B. O. Emikpe, T. O. Jarikre, and O. D. Eyarefe, "Retrospective study of disease incidence and type of pneumonia in Nigerian small ruminants in Ibadan, Nigeria," African Journal of Biomedical Research, vol. 16, no. 2, pp. 107-113, 2013.

[51] J. Arsenault, P. Dubreuil, C. Girard, C. Simard, and D. Bélanger, "Maedi-visna impact on productivity in Quebec sheep flocks (Canada)," Preventive Veterinary Medicine, vol. 59, no. 3, pp. 125-137, 2003.

[52] G. Ayelet, F. Roger, M. Tibbo, and S. Tembely, "Survey of maedi-visna (MV) in Ethiopian highland sheep," The Veterinary Journal, vol. 161, no. 2, pp. 208-210, 2001.

[53] M. Woldemeskel, M. Tibbo, and L. N. D. Potgieter, "Ovine progressive pneumonia (Maedi-Visna): An emerging respiratory disease of sheep in Ethiopia," Deutsche Tierärztliche Wochenschrift, vol. 109, no. 11, pp. 486-488, 2002.

[54] A. M. Getnet, S. Asegedech, and C. Hassen, "Sero-epidemiological study on Maedi-Visna in selected areas of Ethiopia," Ethiopian Veterinary Journal, vol. 14, pp. 101-111, 2010.

[55] M. Woldemeskel and M. Tibbo, "Pulmonary adenomatosis and maedi-visna in Ethiopian central highland sheep: a microscopic study," Tropical Animal Health and Production, vol. 42, no. 5, pp. 995-999, 2010.

[56] Z. Seyoum, M. Bitew, M. Teferi, and E. Gelaye, "Evaluation of control program of maedi-visna by foster feeding with cow colostrum and other measures," Global Veterinaria, vol. 6, no. 1, pp. 91-96, 2011.

[57] F. Tsegaw and Z. Adem, "Serological survey of maedi-visna virus infection in highland sheep at ranches and smallholder farms," Bulletin of Animal Health and Production in Africa, vol. 60, pp. 287-295, 2012.

[58] B. Mekibib, M. Samuel, T. Demisse, and G. Abie, "Concurrent infection of Maedi-Visna with lung worms and pulmonary adenomatosis in sheep kept in Debre Berhan Sheep Improvement Station, Central Ethiopia," Comparative Clinical Pathology, vol. 27, no. 4, pp. 933-938, 2018.

[59] O. Kul, N. Kabakci, H. T. Atmaca, and A. Özkul, "Natural peste des petits ruminants virus infection: novel pathologic findings resembling other morbillivirus infections," Veterinary Pathology, vol. 44, no. 4, pp. 479-486, 2016.

[60] B. O. Emikpe and S. O. Akpavie, "The clinicopathologic effects of Peste des petits ruminants virus infection in West African dwarf goats," Small Ruminant Research, vol. 95, no. 2-3, pp. 168$173,2011$.
[61] A. Khan, M. K. Saleemi, F. Ali et al., "Pathophysiology of peste des petits ruminants in sheep (Dorper \& Kajli) and goats (Boer \& Beetal)," Microbial Pathogenesis, vol. 117, pp. 139-147, 2018.

[62] G. Abraham, A. Sintayehu, G. Libeau et al., "Antibody seroprevalences against peste des petits ruminants (ppr) virus in camels, cattle, goats and sheep in ethiopia," Preventive Veterinary Medicine, vol. 70, no. 1-2, pp. 51-57, 2005.

[63] A. Waret-Szkuta, F. Roger, D. Chavernac et al., "Peste des Petits Ruminants (PPR) in Ethiopia: Analysis of a national serological survey," BMC Veterinary Research, vol. 4, no. 1, article no 34, 2008.

[64] K. Jilo, "Peste des petits ruminants (PPR): global and ethiopian aspects. a standard review," Global Veterinaria, vol. 17, pp. 142153, 2016.

[65] T. S. Haile, M. E. Soma, T. M. Ferki, and A. Beyene, "Seroprevalence of Peste Des Petitis Ruminants (PPR) of sheep and goats in Bench Maji zone, Southern Ethiopia," Global Veterinaria, vol. 19, pp. 622-626, 2017.

[66] B. Suzanna, "Respiratory disease in sheep 2. treatment and control," In Practice, 2008.

[67] Y. Laikemariam, S. Tariku, G. Ayelet, and F. Roger, "Respiratory mycoplasmosis of small ruminants in Ethiopia," Ethiopian Veterinary Journal, vol. 8, pp. 67-74, 2004.

[68] N. A. Antoniassi, S. P. Pavarini, A. Henzel, E. F. Flores, and D. Driemeier, "Aspiration pneumonia associated with oesophageal myonecrosis in sheep due to BTV infection in Brazil," Veterinary Record, vol. 166, no. 2, pp. 52-53, 2010.

[69] A. Lopez, "Respiratory System," in Pathologic Basis of Veterinary Disease, Fourth Mosby Elsevier, M. D. Mcgavin and J. F. Zachary, Eds., pp. 463-546, Mosby Elsevier, 4th edition, 2007.

[70] M. Fentahun, F. Tsegaw, T. Zenebe, M. Tadesse, and A. Robel, "Review on ovine respiratory disease complex in Ethiopia: Significance, causes and possible management methods," Academic Journal of Animal Diseases, vol. 6, pp. 13-22, 2017.

[71] P. R. Scott, Overview of Aspiration Pneumonia, Merck Sharp \& Dohme Corp., a subsidiary of Merck \& Co., Inc., Kenilworth, New York, NJ, USA, 2018, https://www.msdvetmanual.com/ respiratory-system/aspiration-pneumonia/overview-of-aspirationpneumonia.

[72] S. Azizi, E. Tajbakhsh, and F. Fathi, "Ovine pulmonary adenocarcinoma in slaughtered sheep: A pathological and polymerase chain reaction study," Journal of the South African Veterinary Association, vol. 85, no. 1, 5 pages, 2014.

[73] C. Summers, W. Neill, J. M. Sharp et al., "Systemic immune responses following infection with Jaagsiekte sheep retrovirus and in the terminal stages of ovine pulmonary adenocarcinoma," Journal of General Virology, vol. 83, no. 7, pp. 1753-1757, 2002.

[74] G. G. Sonawane, B. N. Tripathi, R. Kumar, and J. Kumar, "Diagnosis and prevalence of ovine pulmonary adenocarcinoma in lung tissues of naturally infected farm sheep," Veterinary World, vol. 9, no. 4, pp. 365-370, 2016. 

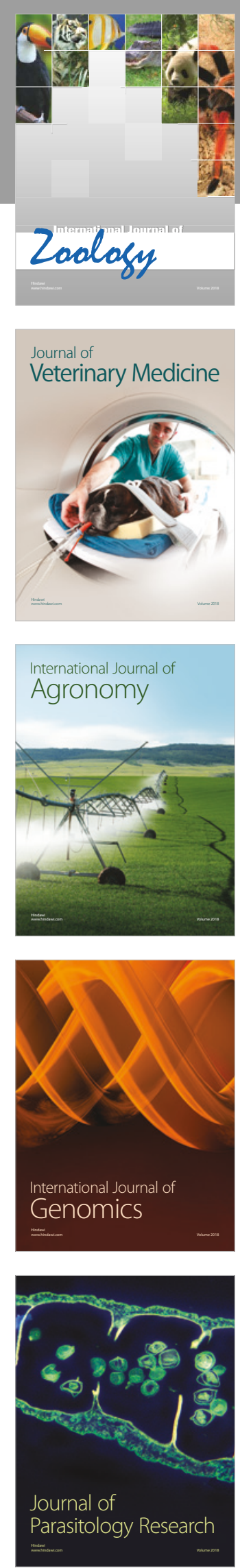

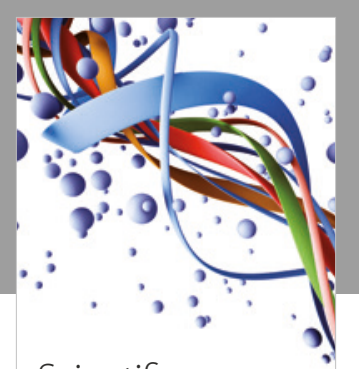

Case Reports in Veterinary Medicine Scientifica
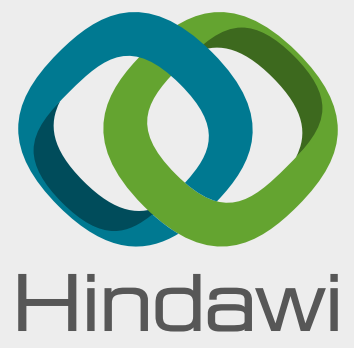

Submit your manuscripts at

www.hindawi.com
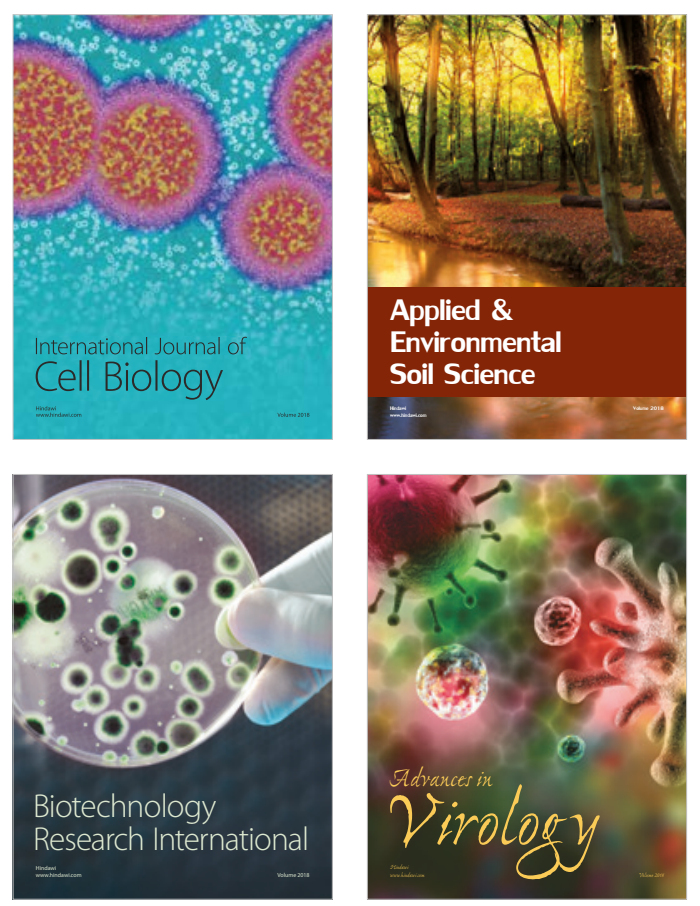

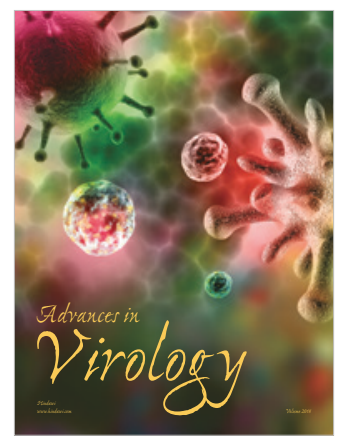

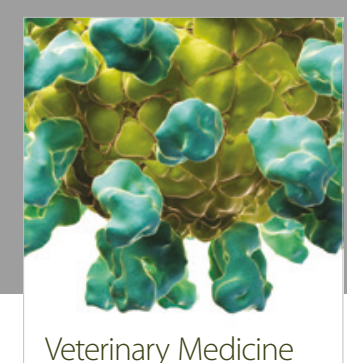
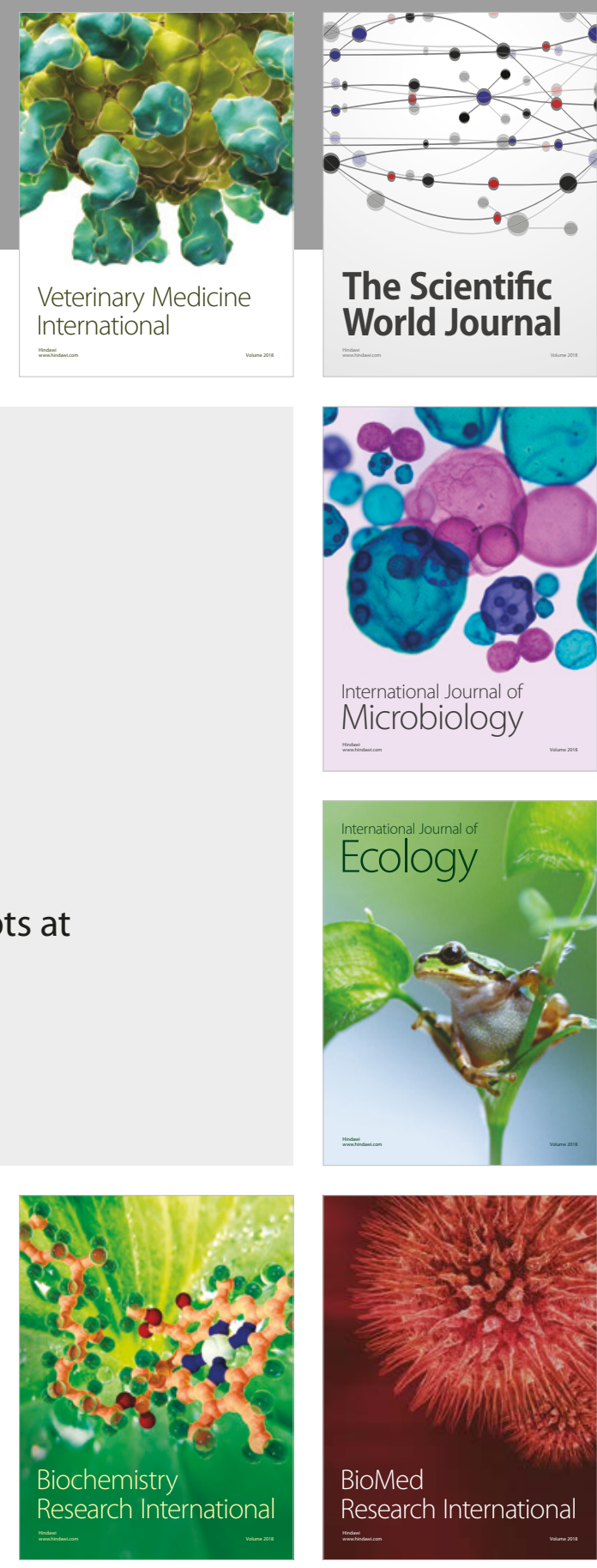

The Scientific World Journal

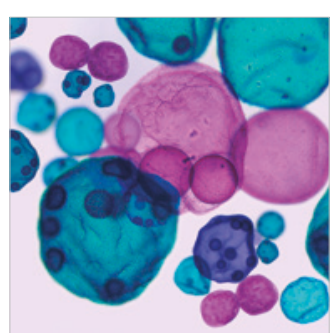

International Journal of Microbiology
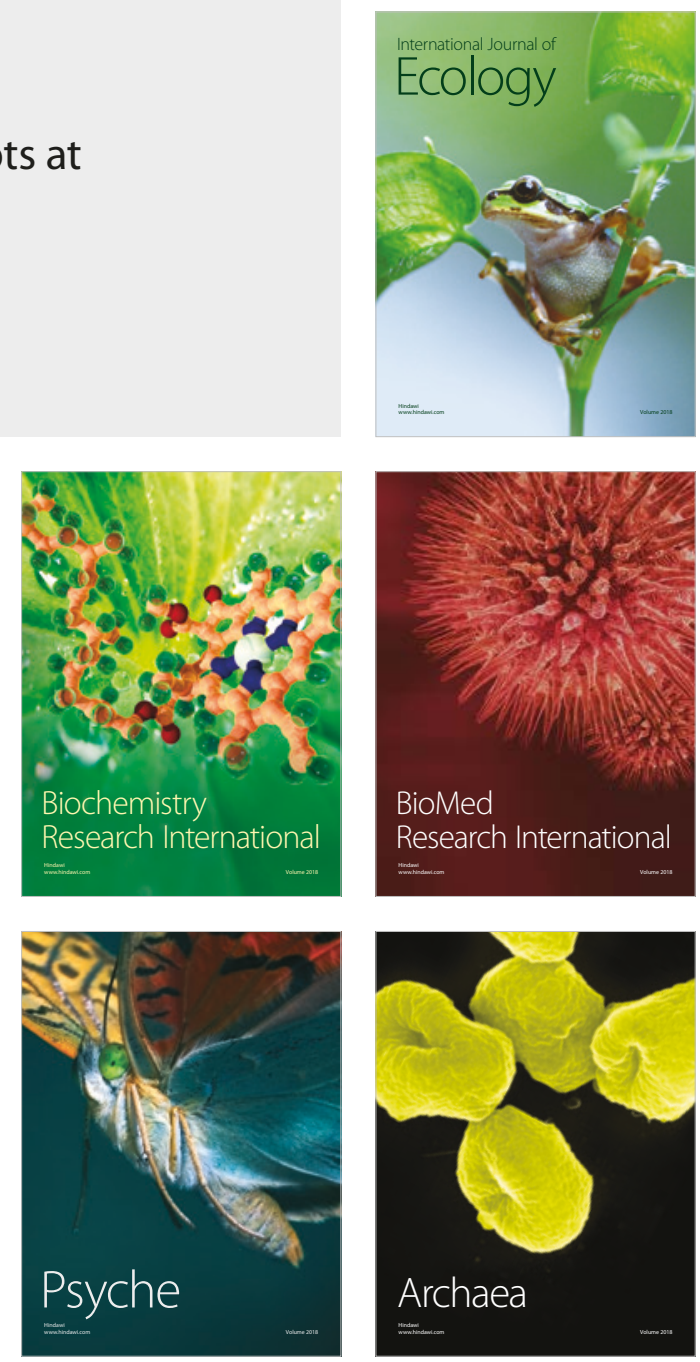